\title{
Characteristics of grain refinement in oxygen-free copper processed by equal-channel angular pressing and dynamic testing
}

\author{
Meshal Y. Alawadhi ${ }^{\mathrm{a}^{*}}$, Shima Sabbaghianrad ${ }^{\mathrm{b}}$, Ying Chun Wang ${ }^{\mathrm{c}}$, \\ Yi Huang ${ }^{\mathrm{d}, \mathrm{e}^{*}}$, Terence G. Langdon ${ }^{\mathrm{e}}$
}

aDepartment of Manufacturing Engineering, College of Technological Studies, P.A.A.E.T, P.O. Box 42325, Shuwaikh 70654, Kuwait

${ }^{b}$ Departments of Aerospace \& Mechanical Engineering and Materials Science, University of Southern California, Los Angeles, CA 90089-1453, USA

${ }^{\mathrm{c} S}$ School of Materials Science and Engineering, Beijing Institute of Technology, Beijing 100081, China

${ }^{\mathrm{d}}$ Department of Design and Engineering, Faculty of Science and Technology, Bournemouth University, Poole, Dorset BH12 5BB, UK

${ }^{\mathrm{e}}$ Materials Research Group, Department of Mechanical Engineering, University of Southampton, Southampton SO17 1BJ, UK

\section{Abstract}

Oxygen-free copper was processed by equal-channel angular pressing (ECAP) at room temperature for 1, 4 and 8 passes and then the ECAP specimens were further deformed by dynamic testing at $298 \mathrm{~K}$ using a strain rate of $10 \mathrm{~s}^{-1}$. Experiments were conducted to investigate the influence of the initial microstructures induced by ECAP on the subsequent grain refinement and mechanical properties after dynamic testing. The results show the strength of copper increased with increasing numbers of ECAP passes and a significant additional grain refinement was produced in the ECAP specimens through the dynamic testing. Thus, the initial grain sizes after ECAP for 1, 4 and 8 passes were $\sim 16, \sim 4.4$ and $\sim 2.9 \mu \mathrm{m}$, respectively, and these values were reduced to $\sim 400, \sim 330$ and $\sim 300 \mathrm{~nm}$ by dynamic testing, The grains were refined by conventional dislocation processes in the 1-pass specimen but there was evidence for dynamic recrystallization in the specimen processed by 8 passes.

\section{Keywords:}

copper; dynamic testing; equal-channel angular pressing; high strain rates; severe plastic deformation.

*Corresponding authors: Meshal Y. Alawadhi (my.alawadhi@PAAET.EDU.KW), Yi Huang (yhuang2@ bournemouth.ac.uk) 


\section{Introduction}

It is now well established that the mechanical properties of materials are enhanced by a reduction in grain size. This enhancement arises because of the Hall-Petch relationship $[1,2]$ which states that the flow stress varies inversely with the grain size raised to a power of $1 / 2$ [3]. Bulk materials having reasonably homogeneous microstructures with grains having sizes of $<1000 \mathrm{~nm}$ are termed ultrafine-grained (UFG) materials [4,5] and when the grain size is smaller than $100 \mathrm{~nm}$ they become nanocrystalline materials and generally exhibit superior and functional properties [6-9]. These materials with exceptionally small grain sizes cannot be obtained using conventional thermomechanical processing but generally they are produced using severe plastic deformation (SPD) in which the material is subjected to a high plastic strain without incurring any significant change in the overall shape of the sample. Various SPD techniques have been developed but the primary methods are equal-channel angular pressing (ECAP) [10], high-pressure torsion (HPT) [11], accumulative roll bonding [12], multidirectional forging [13] and multi-axial compression [14]. Of these procedures, ECAP is especially attractive because it provides a capability for scaling-up and producing relatively large samples [15], an equation is readily available for calculating the strain imposed on the sample [16], the material wastage may be reduced by combining conventional ECAP with Conform-processing [17] and the ECAP samples may be cold rolled into sheets for direct use in superplastic forming operations [18].

Numerous investigations have shown that ECAP is an effective processing tool for the production of a UFG structure in pure copper [19-42]. Generally, the mechanical properties of UFG materials produced by ECAP are examined and reported using quasi-static strain rates as in laboratory-scale tensile and compression tests. However, these tests are conducted over relatively restricted ranges of fairly low strain rates and the properties are generally not extended to high strain rates involving dynamic testing. Some limited results are available 
documenting the properties of pure $\mathrm{Cu}$ when testing dynamically at very high strain rates [4351] but these studies tended to focus on the influence of temperature and strain rate, and especially any coupling effect, that delineated the deformation mechanisms and mechanical properties of the material. Nevertheless, no reports are available to date describing the influence of the initial microstructure on either the mechanical properties or the mechanism of grain refinement in dynamic testing. Recent evaluations have suggested a direct relationship between the initial unprocessed microstructural condition and the minimum grain size obtained after processing by either HPT [52] or ECAP [53].

Accordingly, the present investigation was initiated specifically to evaluate the influence of the initial microstructural condition of oxygen-free copper produced by conducting ECAP at room temperature $(\mathrm{RT} / 298 \mathrm{~K})$ on the subsequent microstructures and properties attained after dynamic testing at a very high strain rate.

\section{Experimental material and procedures}

The investigation was conducted using commercial oxygen-free copper having a purity of $99.95 \%$. Copper billets with a length of $65 \mathrm{~mm}$ and a diameter of $10 \mathrm{~mm}$ were initially annealed in argon for $1 \mathrm{~h}$ using a vacuum tube furnace at a temperature of $873 \mathrm{~K}$ to produce an average grain size of $\sim 24 \mu \mathrm{m}$. The annealed billets were then processed by ECAP at RT using route $\mathrm{B}_{\mathrm{C}}$ in which the sample is rotated by $90^{\circ}$ in the same direction around the longitudinal axis between each pass [54]. Earlier studies showed that this processing route was the most effective in producing an array of equiaxed grains separated by boundaries having high angles of misorientation [55]. The billets were pressed through a solid die for 1, 4 or 8 passes contained within a channel bent through an internal angle of $\Phi=110^{\circ}$ and with an outer $\operatorname{arc}$ of curvature of $\Psi=20^{\circ}$. The imposed strains were estimated using the conventional procedure [16] to give equivalent strains of $\sim 0.76, \sim 3.04$ and $\sim 6.1$ after 1,4 and 8 passes, respectively. 
Following ECAP, the billets were machined into cylindrical samples with diameters of $5 \mathrm{~mm}$ and heights of $5 \mathrm{~mm}$ and they were then tested in uniaxial compression under dynamic conditions at RT at a strain rate of $10 \mathrm{~s}^{-1}$ using a Gleeble 3500 thermal simulator with pressure bars having diameters of $20 \mathrm{~mm}$. Each sample was subjected to a dynamic compressive stress to reach a strain of $\sim 0.68$ where the strain was estimated as $\ln \left(L_{\mathrm{o}} / L_{\mathrm{f}}\right)$ where $L_{\mathrm{o}}$ and $L_{\mathrm{f}}$ are the cylinder heights before and after dynamic testing, respectively.

The microstructures were investigated both after ECAP and after ECAP and dynamic testing using an analytical field emission scanning electron microscope, JEOL JSM-7001 F, at an operating voltage of $15 \mathrm{kV}$. The microstructural images were recorded using electron backscatter diffraction (EBSD) and orientation imaging microscopy (OIM) with OIM ${ }^{\mathrm{TM}}$ software and a TSL orientation-imaging system to collect the experimental data. The EBSD patterns were taken at different working distances with a sample tilt of $70^{\circ}$ and the $\mathrm{OIM}$ images were plotted using a step size of $0.05 \mu \mathrm{m}$.

X-ray diffraction (XRD) scans were performed using a Bruker D2 Phaser X-ray diffractometer equipped with a copper target using $\mathrm{Cu} \mathrm{K \alpha}(\lambda=0.15406 \mathrm{~nm})$ radiation in order to characterize the disc surfaces. The XRD patterns were recorded by performing scans of $\theta-$ $2 \theta$ over $2 \theta=30-100^{\circ}$. MAUD software was employed to perform the profile fitting and the crystallite sizes and microstrain values were used to calculate the dislocation densities.

\section{Experimental results}

\subsection{Microstructures after ECAP}

The microstructural evolution on longitudinal sections of the oxygen-free copper processed by ECAP for (a) 1, (b) 4 and (c) 8 passes (P) at $298 \mathrm{~K}$ is shown by the OIM images in Fig. 1: all of these images illustrate grain sizes that are significantly smaller than the initial average grain size of $\sim 24 \mu \mathrm{m}$. Inspection of Fig. 1(a) shows that the microstructure after 1 pass of ECAP has large and elongated grains with an average size of $\sim 16 \mu \mathrm{m}$. These grains are 
generally aligned in similar directions and they have similar orientations as shown by the unit triangle at lower right. As the imposed strain is increased by processing from 1 to 4 and 8 passes, the microstructure becomes gradually finer with average grain sizes of $\sim 4.4$ and $\sim 2.9$ $\mu \mathrm{m}$ as shown in Fig. 1(b) and (c), respectively. At the highest strain in Fig. 1(c), the microstructure consists of randomly oriented grains but with the grains remaining slightly elongated. This is consistent with earlier results on pure $\mathrm{Cu}$ showing that, when processing by ECAP at RT with a channel angle of $90^{\circ}$ where the imposed strains are higher than with a channel angle of $110^{\circ}$, at least 12 passes are required in order to induce a homogeneous microstructure [31].

Figure 2 presents histograms of the distributions of the grain boundary misorientation angles for specimens processed by ECAP at (a) 1, (b) 4 and (c) 8 passes, where low-angle grain boundaries (LAGBs) have misorientation angles between $2^{\circ}$ and $15^{\circ}$ and high-angle grain boundaries (HAGBs) are defined as misorientations larger than $15^{\circ}$ : these plots correspond to the grain-to-grain misorientation distributions rather than the usual pixel-to-pixel misorientations [56-58] and this effectively eliminates the excess of LAGBs that are visible in the misorientation plots of many earlier investigations [59,60]. After 1 pass the fraction of LAGBs is very high at $\sim 75 \%$ but this fraction decreases to $\sim 34 \%$ and $\sim 29 \%$ after 4 and 8 passes, respectively. The fraction of HAGBs is $\sim 71 \%$ after 8 passes and this is much higher than the value of $\sim 43 \%$ reported earlier for pure $\mathrm{Cu}$ after 8 passes using a die with an angle of $90^{\circ}$ [31]. This difference is due, at least in part, to the earlier use of a pixel-to-pixel distribution which produces an excess of LAGBs.

\subsection{Microstructures after ECAP and dynamic testing}

The OIM images shown in Fig. 3 are for longitudinal sections on the $\mathrm{Cu}$ samples after ECAP and dynamic testing at a strain rate of $10 \mathrm{~s}^{-1}$ at RT: the initial ECAP processing for these images was (a) 1, (b) 4 and (c) 8 passes, respectively. The images display ultrafine grains that 
are slightly elongated after ECAP for 1 pass but reasonably equiaxed after 4 and 8 passes. For each image, all grains have a range of misorientations as shown by the unit triangle at the lower right. The measured average grain sizes for these conditions were $\sim 400, \sim 330$ and $\sim 300 \mathrm{~nm}$ after processing by ECAP for 1, 4 and 8 passes, respectively. It is readily apparent by comparison with Fig. 1 that the grain size is reduced after higher numbers of passes of ECAP and it follows from Fig. 3 that even further reductions in grain size are achieved when testing dynamically at RT.

Histograms of the distributions of the grain boundary misorientations are shown in Fig. 4 for the samples tested dynamically after initially processing by ECAP for (a) 1, (b) 4 and (c) 8 passes. An examination of these results shows that the fractions of HAGBs are now similar at $\sim 85 \%$ for all samples. This means that the fraction of HAGBs increases for all of these samples during the dynamic testing, even for the sample initially processed through 8 passes where there is an increase from $\sim 71 \%$ to $\sim 85 \%$.

\subsection{Mechanical behavior in dynamic compression and significance of XRD measurements}

Figure 5 shows the true stress-true strain curves in dynamic compression for samples processed initially through 1,4 and 8 passes. All curves are similar but nevertheless the strength increases with increasing numbers of initial passes. The estimated yield strengths were measured as $\sim 350, \sim 420$ and $\sim 450 \mathrm{MPa}$ after processing by ECAP for 1, 4 and 8 passes, respectively, where these results are consistent with data reported for cold-rolled oxygen-free high conductivity (OFHC) $\mathrm{Cu}$ tested dynamically using a split Hopkinson pressure bar with a strain rate of $2500 \mathrm{~s}^{-1}[49]$.

X-ray diffraction testing was performed to provide additional insight into the deformation mechanisms and microstructural evolution of the $\mathrm{Cu}$ specimens processed by ECAP and further deformed by dynamic testing. The increase in strength with increasing numbers of preliminary ECAP passes was confirmed by the X-ray diffraction analysis and 
Table 1 summarizes the calculated crystallite sizes and dislocation densities as a function of the initial number of ECAP passes followed by dynamic testing using a strain rate of $10 \mathrm{~s}^{-1}$ at RT. The dislocation density was calculated from the X-ray data using the relationship $[61,62]$

$$
\rho=\frac{2 \sqrt{3}<\varepsilon^{2}>^{1 / 2}}{D_{c} b}
$$

where $\left\langle\varepsilon^{2}>^{1 / 2}\right.$ is the lattice microstrain, $\mathrm{D}_{\mathrm{C}}$ is the average crystallite size and $\mathrm{b}$ is the Burgers vector. The values for the microstrain and crystallite size were extracted from an analysis of the X-ray diffraction line-broadening using MAUD software [63]. The calculations show that the dislocation density increases and the crystallite size decreases after dynamic testing with increasing numbers of preliminary ECAP passes. Thus, the calculated dislocation density after testing the 1 pass specimen was $\sim 6.11 \times 10^{13} \mathrm{~m}^{-2}$ but this increased to $\sim 1.12 \times 10^{14} \mathrm{~m}^{-2}$ and $\sim 1.78 \times 10^{14} \mathrm{~m}^{-2}$ for the 4 and 8 pass specimens, respectively. It is noted that this is consistent with the increasing strength with increasing ECAP passes shown in Fig. 5 so that the highly deformed copper with the smallest crystallite size and highest dislocation density exhibits the highest strength during dynamic testing at RT. This suggests that pre-existing internal stresses created during ECAP may significantly influence the microstructure and it confirms the association between the initial microstructural condition produced by ECAP and the mechanical strength obtained after dynamic testing.

\subsection{A direct comparison between the initial microstructural condition and the microstructure}

\section{after dynamic testing}

In order to fully analyse the results from dynamic testing, it is necessary to consider the initial microstructural condition prior to the dynamic tests and especially the imposed numbers of ECAP passes.

Table 2 provides a comprehensive summary of the measured dislocation density and grain size for the annealed condition, for the condition after ECAP and after ECAP and dynamic testing at a strain rate of $10 \mathrm{~s}^{-1}$ at RT for 1,4 and 8 passes. For all three ECAP 
conditions, the grain size is significantly reduced after additional dynamic testing but the dislocation density increases with dynamic testing for both the 1 and 4 pass samples whereas it decreases after dynamic testing for 8 passes. In addition, it is apparent that, by comparison with the initial as-annealed condition, consistently higher values of the dislocation densities are produced after processing by ECAP and by ECAP followed by dynamic testing. The calculated dislocation density for the as-annealed specimen is $\sim 3.9 \times 10^{12} \mathrm{~m}^{-2}$ but, although dynamic testing successfully reduces the grain sizes for the specimens processed by ECAP, the dislocation density rises to $\sim 6.11 \times 10^{13} \mathrm{~m}^{-2}$ for 1 pass ECAP + dynamic testing and this is higher than the value of $\sim 3.98 \times 10^{13} \mathrm{~m}^{-2}$ after 1 pass of ECAP. Finally, it is noted that the dislocation density of $\sim 1.78 \times 10^{14} \mathrm{~m}^{-2}$ after 8 passes of ECAP and dynamic testing is lower than the density of $\sim 3.60 \times 10^{14} \mathrm{~m}^{-2}$ calculated after 8 passes of ECAP without dynamic testing.

\section{Discussion}

\subsection{Influence of initial microstructure on strength of oxygen-free copper}

In practice there are uncertainties regarding the influence of the initial microstructural condition produced by ECAP on the microstructure and mechanical properties attained after high strain rate dynamic testing and therefore the present results must be interpreted with caution. Nevertheless, it is noted that the copper samples underwent significant plastic deformation during the ECAP process and the strain accumulated after each pass entailed the introduction of more dislocations and additional grain refinement.

The 8 pass sample has a higher level of internal stress and dislocation density compared to the 1 and 4 pass specimens and therefore it is in a state of relatively high stress. This may introduce strain hardening that is induced by the ECAP prior to the dynamic testing. It is evident from Fig. 2 that the 8 passes specimen has a high fraction of HAGBs of $71 \%$ and this exceeds both the 1 and 4 passes samples. This leads to prominent work hardening in the ECAPprocessed copper after 8 passes due to a combination of grain boundary and dislocation 
strengthening mechanisms. Thus, the higher strain imposed during ECAP to higher numbers of passes generates more dislocations and produces smaller grains that hinder dislocation motion in the subsequent dynamic tests.

It is apparent from Fig. 3 that dynamic testing at RT using a strain rate of $10 \mathrm{~s}^{-1}$ leads to a further increase in the fraction of HAGBs and also to additional grain refinement as shown in Fig. 3. Thus, it is clear from Fig. 5 that the level of the steady-state stress increases in dynamic testing with additional numbers of initial ECAP passes and it is concluded that the variation of strength observed after dynamic testing is related directly to differences in the initial microstructural conditions produced by the ECAP processing. During deformation in SPD processing, the level of the internal stresses and the dislocation densities increase and create arrays of non-equilibrium boundaries [64,65] and in practice processing through different strains generates different numbers of geometrically necessary dislocations. This is reflected directly in the strength of the oxygen-free copper specimens after dynamic testing as shown in Fig. 5. It is also apparent from the data recorded in Table 1 that the specimen processed through ECAP for 8 passes exhibits the highest dislocation density and the smallest crystallite size by comparison with specimens processed through lower numbers of passes.

Close inspection of Fig. 5 shows that the strength initially increases with increase in the initial imposed strain but the gain in strength decreases at true strains above $\sim 0.05$. After levelling off to reasonable steady-state conditions, there is a larger gap between 1 and 4 passes than between 4 and 8 passes. Similarly, there is a larger decrease in crystallite size when increasing the ECAP passes from 1 to 4 as shown in Table 1 . This trend is related to the increase in the numbers of geometrically necessary dislocations. The density of these dislocations increases with increasing strain and as the density increases so it becomes more difficult to accommodate additional dislocations. Consequently, a microstructural saturation is reached 
when the strain exceeds a critical value. This saturation occurs when the processes of generation and annihilation of dislocations become reasonably balanced.

It follows from Fig. 1 that ECAP through 1, 4 and 8 passes produces only the initial stages in the process of grain fragmentation and it is not sufficient to fully form a homogeneous microstructure with equiaxed grains. This shows that the strain imposed by ECAP is lower than the critical strain required to achieve a steady-state saturation condition. The different low strain conditions produced by ECAP create different initial microstructures but the subsequent dynamic testing at a well-defined strain rate adds similar levels of strain hardening to each condition. Therefore, the conditions with the highest levels of internal stresses and dislocation densities prior to the dynamic testing produce the highest mechanical strength as is evident in Fig. 5. These results are consistent with a study showing that the initial microstructural condition produced by ECAP prior to further processing by HPT can significantly affect the final grain size [66] and also with an investigation showing that the maximum shear stress increases with increasing numbers of ECAP passes prior to dynamic torsional testing [67].

\subsection{Significance of grain refinement during dynamic testing}

It is apparent from Fig. 3 that there is significant grain refinement during the dynamic testing at RT when using a strain rate of $10 \mathrm{~s}^{-1}$. Specifically, the grain structure formed by the ECAP processing contains large and elongated grains as shown in Fig. 1 and this evolves into a microstructure composed of fine grains with nearly equiaxed shapes as shown in Fig. 3. It can be seen also that the microstructure evolves towards greater homogeneity and the grains became more equiaxed by increasing the numbers of ECAP passes from 1 to 8 prior to the dynamic testing

The most interesting finding is that dynamic testing is effective in producing exceptional UFG structures within specimens that were initially subjected to processing by ECAP. Table 3 shows a comparison between the average grain sizes produced by ECAP + 
dynamic testing and the average grain sizes produced by various SPD techniques. It follows from Table 3 that deforming copper by dynamic testing is effective in producing very small grain sizes within the nanometer range and these values are similar to those produced after processing by a single or combination of SPD techniques at RT such as HPT [68,71,73-75], ECAP $[20,69,71,72,75]$, ECAP + HPT $[71,75,76]$ and surface mechanical attrition treatment (SMAT) [70].

During dynamic testing, high strain rate deformation is induced in the specimen by the high velocity impact. Dislocation gliding, interactions, tangling and spatial rearrangements take place to accommodate these high strains and this increases the dislocation density. Accordingly, the formation of dislocation tangles and walls of dislocations transform into subgrain boundaries within the grains and thereby produce a UFG structure. This is similar to the grain refinement mechanism observed in SPD for various metals including copper processed by HPT [77,78] and it is similar also to the mechanisms reported in a 7075 aluminium alloy processed by laser shock processing (LSP) [79] and $\mathrm{Mg} / \mathrm{Ti}$ joints by high energy shot peening (HESP) [80]. It follows from Table 1 that grain refinement after dynamic testing is associated with a substantial increase in the dislocation density and this is consistent with earlier studies showing higher dislocation densities produced through the use of multiple SPD procedures $[71,81,82]$. Despite this success, it is important to note that dynamic testing does not constitute a true SPD processing method because, contrary to the formal definition of SPD techniques [4], the shape and size of the specimens are not retained during testing.

Nevertheless, the microstructures for the 8 passes specimen developed after dynamic testing at RT consists of reasonably equiaxed ultrafine grains and it appears that the microstructure may be changed by dynamic recrystallization (DRX) during the dynamic testing. The possibility of the occurrence of DRX in pure copper during processing at a high strain rate was suggested in an early report [83] and it was proposed that DRX may take place 
at the subgrain boundaries and produce ultrafine grains having HAGBs [84]. This agrees with earlier studies reporting the evolution of small grains having HAGBs through DRX at high strain rates $[83,85-87]$.

Early reports proposed that the thermal effects of the adiabatic temperature rise may significantly enhance DRX during high strain rate deformation [85,88]. Thus, high speed compression generates adiabatic heating and stores considerable energy within the material which may provide a driving force for DRX in the form of microstructural reorganisation through the migration of HAGBs $[89,90]$. The adiabatic temperature rise in oxygen-free copper during high strain deformation can be calculated using the expression [91]

$$
\Delta T=\frac{0.9}{\rho C_{V}} \int_{0}^{\varepsilon} \sigma d \varepsilon
$$

where $\sigma$ and $\varepsilon$ are the true stress and true strain, respectively, $\rho$ is the density of the material $\left(8.96 \mathrm{~g} / \mathrm{cm}^{3}\right)$ and $C_{V}$ is the specific heat capacity of copper $(383 \mathrm{~J} / \mathrm{kg} \mathrm{K})$. The calculated temperature rise for the 8 passes specimen deformed at the dynamic strain rate of $10 \mathrm{~s}^{-1}$ is $\sim 375$ $\mathrm{K}$. This is lower than an adiabatic temperature rise in the range of $\sim 500-800 \mathrm{~K}$ calculated for copper during dynamic deformation at a much higher strain rate of $10^{4} \mathrm{~s}^{-1}$ [85] but it is higher than the adiabatic temperature rise of $\sim 300 \mathrm{~K}$ estimated for copper during shock-loading impacts [88]. Both of these studies proposed that the adiabatic temperature rise can cause microstructural development by DRX. A later study reported an adiabatic temperature rise of $500 \mathrm{~K}$ under compression for shock-hardened copper at high strain rates [86] but the total time for cooling the specimen to RT was estimated as less than $1600 \mu$ s so that there was a minor influence of temperature on DRX.

It is readily noted from the results in this study that grain refinement in oxygen-free copper can be produced by DRX depending on the initial microstructure prior to the dynamic testing. Thus, the 1 pass specimen has a larger grain size and a higher proportion of LAGBs (Fig. 2(a)) so that it can accommodate more dislocations during dynamic testing. Therefore, 
the grain refinement mechanism in this specimen is mainly due to dislocation activities. Conversely, the 8 passes specimen has a smaller grain size, a higher fraction of HAGBs (Fig. 2(c)) and a higher dislocation density (Table 1) which provide a greater potential for the advent of DRX. Since the adiabatic temperature rise during high strain rate dynamic testing has a minor influence on the microstructure, it is proposed that the microstructure evolved in this specimen through mechanically-induced DRX [86,92]. It should be noted that this mechanism for grain refinement in the 8 passes specimen is similar to earlier studies on an aluminium alloy [93] and on ANSI-type 304 stainless steel [94] when dynamically deformed by laser shock processing.

\section{Summary and conclusions}

1. Oxygen-free $\mathrm{Cu}$ was processed by ECAP for 1,4 and 8 passes at room temperature and then further deformed by dynamic testing at $298 \mathrm{~K}$ using a strain rate of $10 \mathrm{~s}^{-1}$.

2. After dynamic testing the results show that each condition has different strengths, dislocation densities, average grain sizes and crystallite sizes. The yield strength and dislocation density increase and the grain and crystallite sizes decrease with increasing numbers of ECAP passes prior to dynamic testing.

3. The mechanical properties after dynamic testing are influenced by the initial microstructural conditions produced by ECAP. Thus, when these conditions are close to saturation prior to dynamic testing so the effect of dynamic testing on the mechanical properties and microstructure is reduced.

4. The pre-existing stresses and dislocation density produced by ECAP influence the grain refinement mechanism during dynamic testing. The highly stressed specimen processed through 8 passes provides a high driving force for DRX during dynamic testing whereas the 1 pass specimen is able to accommodate more dislocations so that grain refinement occurs 
through conventional dislocation activities. It appears that the microstructure of the 8 passes specimen probably evolves through mechanically-induced DRX

5. The results establish that dynamic testing provides an effective additional tool for the production of ultrafine and equiaxed grains having a high fraction of high-angle grain boundaries.

\section{Acknowledgements}

This work was supported by the European Research Council under ERC Grant Agreement No. 267464-SPDMETALS, the Public Authority for Applied Education and Training in Kuwait and the National Natural Science Foundation of China under Grant No. 51671030.

\section{Data Availability}

The raw/processed data required to reproduce these findings cannot be shared at this time as the data also forms part of an ongoing study. 


\section{References}

[1] E.O. Hall, The deformation and ageing of mild steel: III Discussion of results, Proc. Phys. Soc. B 64 (1951) 747-753.

[2] N.J. Petch, Cleavage strength of polycrystals, J. Iron Steel Inst. 174 (1953) 25-28.

[3] N. Balasubramanian, T.G. Langdon, The strength-grain size relationship in ultrafinegrained metals, Metall. Mater. Trans. A 47A (2016) 5827-5838.

[4] R.Z. Valiev, Y. Estrin, Z. Horita, T.G. Langdon, M.J. Zehetbauer, Y.T. Zhu, Producing bulk ultrafine-grained materials by severe plastic deformation, JOM 58 (4) (2006) 3339.

[5] R.Z. Valiev, Y. Estrin, Z. Horita, T.G. Langdon, M.J. Zehetbauer, Y. Zhu, Producing bulk ultrafine-grained materials by severe plastic deformation: Ten years later, JOM 68 (2016) 1216-1226.

[6] Y.T. Zhu, T.C. Lowe, T.G. Langdon, Performance and applications of nanostructured materials produced by severe plastic deformation, Scripta Mater. 51 (2004) 825-830.

[7] T.G. Langdon, Twenty-five years of ultrafine-grained materials: Achieving exceptional properties through grain refinement, Acta Mater. 61 (2013) 7035-7059.

[8] R.Z. Valiev, A.P. Zhilyaev, T.G. Langdon, Bulk Nanostructured Materials: Fundamentals and Applications, Wiley/TMS, Hoboken, NJ, USA (2014).

[9] R.Z. Valiev, Y. Estrin, Z. Horita, T.G. Langdon, M.J. Zehetbauer, Y.T. Zhu, Fundamentals of superior properties in bulk nanoSPD materials, Mater. Res. Lett. 4 (2016) 1-21.

[10] R.Z. Valiev, T.G. Langdon, Principles of equal-channel angular pressing as a processing tool for grain refinement, Prog. Mater. Sci. 51 (2006) 881-981.

[11] A.P. Zhilyaev, T.G. Langdon, Using high-pressure torsion for metal processing: Fundamentals and applications, Prog. Mater. Sci. 53 (2008) 893-979. 
[12] Y. Saito, N. Tsuji, H. Utsunomiya, T. Sakai, R.G. Hong, Ultra-fine grained bulk aluminum produced by accumulative roll-bonding (ARB) process, Scripta Mater. 39 (1998) 1221-1227.

[13] S.V. Zherebtsov, G.A. Salishchev, R.M. Galeyev, O.R. Valiakhmetov, S.Yu. Mironov, S.I. Semiatin, Production of submicrocrystalline structure in large-scale Ti-6Al-4V billet by warm severe deformation processing, Scripta Mater. 51 (2004) 1147-1151.

[14] X. Xu, Q. Zhang, N. Hu, Y. Huang, T.G. Langdon, Using an Al-Cu binary alloy to compare processing by multi-axial compression and high-pressure torsion, Mater. Sci. Eng. A588 (2013) 280-287.

[15] P.K. Chaudhury, B. Cherukuri, R. Srinivasan, Scaling up of equal-channel angular pressing and its effect on mechanical properties, microstructure, and hot workability of AA 6061, Mater. Sci. Eng. A410-411 (2005) 316-318.

[16] Y. Iwahashi, J. Wang, Z. Horita, M. Nemoto, T.G. Langdon, Principle of equal-channel angular pressing for the processing of ultra-fine grained materials, Scripta Mater. 35 (1996) 143-146.

[17] G.J. Raab, R.Z. Valiev, T.C. Lowe, Y.T. Zhu, Continuous processing of ultrafine grained Al by ECAP-Conform, Mater. Sci. Eng. A382 (2004) 30-34.

[18] H. Akamatsu, T. Fujinami, Z. Horita, T.G. Langdon, Influence of rolling on the superplastic behavior of an Al-Mg-Sc alloy after ECAP, Scripta Mater. 44 (2001) 759764.

[19] R.Z. Valiev, E. V. Kozlov, Y.F. Ivanov, J. Lian, A.A. Nazarov, B. Baudelet, Deformation behaviour of ultra-fine-grained copper, Acta Metall. Mater. 42 (1994) 2467-2475.

[20] S. Komura, Z. Horita, M. Nemoto, T.G. Langdon, Influence of stacking fault energy on microstructural development in equal-channel angular pressing, J. Mater. Res. 14 (1999) 4044-4050. 
[21] W.H. Huang, L. Chang, P.W. Kao, C.P. Chang, Effect of die angle on the deformation texture of copper processed by equal channel angular extrusion, Mater. Sci. Eng. A307 (2001) 113-118.

[22] H.W. Höppel, Z.M. Zhou, H. Mughrabi, R.Z. Valiev, Microstructural study of the parameters governing coarsening and cyclic softening in fatigued ultrafine-grained copper, Philos. Mag. A. 82 (2002) 1781-1794.

[23] S.D. Wu, Z.G. Wang, C.B. Jiang, G.Y. Li, I.V. Alexandrov, R.Z. Valiev, The formation of PSB-like shear bands in cyclically deformed ultrafine grained copper processed by ECAP, Scripta Mater. 48 (2003) 1605-1609.

[24] K. Neishi, Z. Horita, T.G. Langdon, Achieving superplasticity in ultarfine-grained copper: Influence of Zn and Zr additions, Mater. Sci. Eng. A352 (2003) 129-135.

[25] F. Dalla Torre, R. Lapovok, J. Sandlin, P.F. Thomson, C.H.J. Davies, E.V. Pereloma, Microstructures and properties of copper processed by equal channel angular extrusion for 1-16 passes, Acta Mater. 52 (2004) 4819-4832.

[26] M. Furukawa, Y. Fukuda, K. Oh-ishi, Z. Horita, T.G. Langdon, An investigation of deformation in copper single crystals using equal-channel angular pressing, Mater. Sci. Forum 503-504 (2006) 113-118.

[27] Y.H. Zhao, J.F. Bingert, X.Z. Liao, B.Z. Cui, K. Han, A.V. Sergueeva, A.K. Mukherjee, R.Z. Valiev, T.G. Langdon, Y.T. Zhu, Simultaneously increasing the ductility and strength of ultrafine-grained pure copper, Adv. Mater. 18 (2006) 2949-2953.

[28] M. Furukawa, Z. Horita, T.G. Langdon, Application of equal-channel angular pressing to aluminum and copper single crystals, Mater. Sci. Forum 539-543 (2007) 2853-2858.

[29] Y. Fukuda, K. Oh-ishi, M. Furukawa, Z. Horita, T.G. Langdon, Influence of crystal orientation on the processing of copper single crystals by ECAP, J. Mater. Sci. 42 (2007) $1501-1511$. 
[30] A.P. Zhilyaev, S. Swaminathan, A.A. Gimazov, T.R. McNelley, T.G. Langdon, An evaluation of microstructure and microhardness in copper subjected to ultra-high strains, J. Mater. Sci. 43 (2008) 7451-7456.

[31] C.X. Huang, H.J. Yang, S.D. Wu, Z.F. Zhang, Microstructural characterizations of Cu processed by ECAP from 4 to 24 passes, Mater. Sci. Forum. 586 (2008) 333-337.

[32] M. Furukawa, Z. Horita, T.G. Langdon, Microstructures of aluminum and copper single crystals processed by equal-channel angular pressing, Mater. Sci. Forum 638-642 (2010) 1946-1951.

[33] Z.J. Zhang, Q.Q. Duan, X.H. An, S.D. Wu, G. Yang, Z.F. Zhang, Microstructure and mechanical properties of $\mathrm{Cu}$ and $\mathrm{Cu}-\mathrm{Zn}$ alloys produced by equal channel angular pressing, Mater. Sci. Eng. A528 (2011) 4259-4267.

[34] Q.W. Jiang, X.W. Li, Effect of pre-annealing treatment on the compressive deformation and damage behavior of ultrafine-grained copper, Mater. Sci. Eng. A546 (2012) 59-67.

[35] N.D. Stepanov, A. V. Kuznetsov, G.A. Salishchev, G.I. Raab, R.Z. Valiev, Effect of cold rolling on microstructure and mechanical properties of copper subjected to ECAP with various numbers of passes, Mater. Sci. Eng. A554 (2012) 105-115.

[36] C.X. Huang, W. Hu, G. Yang, Z.F. Zhang, S.D. Wu, Q.Y. Wang, G. Gottstein, The effect of stacking fault energy on equilibrium grain size and tensile properties of nanostructured copper and copper-aluminum alloys processed by equal channel angular pressing, Mater. Sci. Eng. A556 (2012) 638-647.

[37] A.P. Zhilyaev, T.G. Langdon, Microhardness and EBSD microstructure mapping in partially-pressed $\mathrm{Al}$ and $\mathrm{Cu}$ through $90^{\circ}$ ECAP die, Mater. Res. 16 (2013) 586-591.

[38] A.P. Zhilyaev, I. Shakova, A. Belyakov, R. Kaibyshev, T.G. Langdon, Wear resistance and electroconductivity in copper processed by severe plastic deformation, Wear 305 (2013) 89-99. 
[39] W. Blum, J. Dvořák, P. Král, P. Eisenlohr, V. Sklenička, Effect of grain refinement by ECAP on creep of pure Cu, Mater. Sci. Eng. A590 (2014) 423-432.

[40] J. Li, J. Xu, B. Guo, D. Shan, T.G. Langdon, Shear-fracture mechanism in micro-tension of an ultrafine-grained pure copper using synchrotron radiation X-ray tomography, Scripta Mater. 132 (2017) 25-29.

[41] M.Y. Alawadhi, Y. Huang, T.G. Langdon, Evolution of homogeneity in oxygen-free copper processed by ECAP or HPT, Rev. Adv. Mater. Sci. 50 (2017) 47-54.

[42] M.Y. Alawadhi, S. Sabbaghianrad, Y. Huang, T.G. Langdon, Direct influenece of recovery behaviour on mechanical properties in oxygen-free copper processed using different SPD techniques: HPT and ECAP, J. Mater. Res. Tech. 6 (2017) 369-377.

[43] U. Andrade, M.A. Meyers, K.S. Vecchio, A.H. Chokshi, Dynamic recrystallization in high-strain, high-strain-rate plastic-deformation of copper, Acta Metall. Mater. 42 (1994) $3183-3195$.

[44] M.A. Meyers, U.R. Andrade, A.H. Chokshi, The effect of grain size on the high-strain, high-strain-rate behavior of copper, Metall. Mater. Trans. A 26A (1995) 2881-2893.

[45] J.A. Hines, K.S. Vecchio, Recrystallization kinetics within shear bands adiabatic, Acta Metall. 45 (1997) 635-649.

[46] G.T. Gray, T.C. Lowe, C.M. Cady, R.Z. Valiev, I. V. Aleksandrov, Influence of strain rate and temperature on the mechanical response of ultrafine-grained $\mathrm{Cu}, \mathrm{Ni}$, and $\mathrm{Al}$ 4Cu-0.5Zr, Nanostruct. Mater. 9 (1997) 477-480.

[47] W.S. Zhao, N.R. Tao, J.Y. Guo, Q.H. Lu, K. Lu, High density nano-scale twins in Cu induced by dynamic plastic deformation, Scripta Mater. 53 (2005) 745-749.

[48] Y.S. Li, N.R. Tao, K. Lu, Microstructural evolution and nanostructure formation in copper during dynamic plastic deformation at cryogenic temperatures, Acta Mater. 56 (2008) 230-241. 
[49] A. Mishra, M. Martin, N.N. Thadhani, B.K. Kad, E.A. Kenik, M.A. Meyers, High-strainrate response of ultra-fine-grained copper, Acta Mater. 56 (2008) 2770-2783.

[50] T. Suo, Y. Li, K. Xie, F. Zhao, K.-S. Zhang, Q. Deng, Experimental investigation on strain rate sensitivity of ultra-fine grained copper at elevated temperatures, Mech. Mater. 43 (2011) 111-118.

[51] T. Suo, Y. Li, F. Zhao, X. Fan, W. Guo, Compressive behavior and rate-controlling mechanisms of ultrafine grained copper over wide temperature and strain rate ranges, Mech. Mater. 61 (2013) 1-10.

[52] F.A. Mohamed, S.S. Dheda, On the minimum grain size obtainable by high-pressure torsion, Mater. Sci. Eng. A558 (2012) 59-63.

[53] F.A. Mohamed, S.S. Dheda, On the minimum grain size obtainable by equal channel angular pressing, Mater. Sci. Eng. A580 (2013) 227-230.

[54] M. Furukawa, Y. Iwahashi, Z. Horita, M. Nemoto, T.G. Langdon, The shearing characteristics associated with equal-channel angular pressing, Mater. Sci. Eng. A257 (1998) 328-332.

[55] K. Oh-ishi, Z. Horita, M. Furukawa, M. Nemoto, T.G. Langdon, Optimizing the rotation conditions for grain refinement in equal-channel angular pressing, Metall. Mater. Trans. A 29A (1998) 2011-2013.

[56] L.S. Tóth, B. Beausir, C.F. Gu, Y. Estrin, N. Scheerbaum, C.H.J. Davies, Effect of grain refinement by severe plastic deformation on the next-neighbor misorientation distribution, Acta Mater. 58 (2010) 6706-6716.

[57] L.S. Toth, C.F. Gu, Modeling of disorientation axis distribution in severely deformed copper, Scripta Mater. 69 (2013) 183-186.

[58] L.S. Toth, C.F. Gu, Ultrafine-grain metals by severe plastic deformation, Mater. Charact. $92(2014) 1-14$. 
[59] J. Wongsa-Ngam, H. Wen, T.G. Langdon, Microstructural evolution in a Cu-Zr alloy processed by a combination of ECAP and HPT, Mater. Sci. Eng. A579 (2013) 126-135.

[60] J. Wongsa-Ngam, M. Kawasaki, T.G. Langdon, A comparison of microstructures and mechanical properties in a $\mathrm{Cu}-\mathrm{Zr}$ alloy processed using different SPD techniques, J. Mater. Sci. 48 (2013) 4653-4660.

[61] G. Williamson, R. Smallman, III. Dislocation densities in some annealed and coldworked metals from measurements on the X-ray debye-scherrer spectrum, Philos. Mag. 1 (1956) 34-46.

[62] R. Smallman, K. Westmacott, Stacking faults in face-centred cubic metals and alloys, Philos. Mag. 2 (1957) 669-683.

[63] L. Lutterotti, S. Matthies, H.R. Wenk, MAUD (Material Analysis Using Diffraction): a user friendly Java program for Rietveld texture analysis and more, Proc. ICOTOM-12, NRC Research Press, Ottawa, Canada, pp. 1599-1604 (1999).

[64] J. Wang, Z. Horita, M. Furukawa, M. Nemoto, N.K. Tsenev, R.Z. Valev, Y. Ma, T.G. Langdon, An investigation of ductility and microstructural evolution in an Al-3\% $\mathrm{Mg}$ alloy with submicron grain size, J. Mater. Res. 8 (1993) 2810-2818.

[65] J. Wang, Y. Iwahashi, Z. Horita, M. Furukawa, M. Nemoto, R.Z. Valiev, T.G. Langdon, An investigation of microstructural stability in an Al-Mg alloy with submicrometer grain size, Acta Mater. 44 (1996) 2973-2982.

[66] S. Sabbaghianrad, T.G. Langdon, A critical evaluation of the processing of an aluminum 7075 alloy using a combination of ECAP and HPT, Mater. Sci. Eng. A. 596 (2014) 5258.

[67] Y.G. Kim, B. Hwang, S. Lee, C.W. Lee, D.H. Shin, Dynamic deformation and fracture behavior of ultra-fine-grained pure copper fabricated by equal channel angular pressing, Mater. Sci. Eng. A. 504 (2009) 163-168. 
[68] Z. Horita, T.G. Langdon, Microstructures and microhardness of an aluminum alloy and pure copper after processing by high-pressure torsion, Mater. Sci. Eng. A. 410-411 (2005) 422-425.

[69] N. Lugo, N. Llorca, J.J. Suñol, J.M. Cabrera, Thermal stability of ultrafine grains size of pure copper obtained by equal-channel angular pressing, J. Mater. Sci. 45 (2010) $2264-2273$.

[70] K. Wang, N.R. Tao, J. Liu, K. Lu, Plastic strain-induced grain refinement in the nanometer scale in copper, Acta Mater. 54 (2006) 5281-5291.

[71] A.P. Zhilyaev, A.A. Gimazov, G.I. Raab, T.G. Langdon, Using high-pressure torsion for the cold-consolidation of copper chips produced by machining, Mater. Sci. Eng. A. 486 (2008) 123-126.

[72] S.V. Dobatkin, J.A. Szpunar, A.P. Zhilyaev, J.-Y. Cho, A.A. Kuznetsov, Effect of the route and strain of equal-channel angular pressing on structure and properties of oxygen-free copper, Mater. Sci. Eng. A. 462 (2007) 132-138.

[73] K.J. Al-Fadhalah, S.N. Alhajeri, A.I. Almazrouee, T.G. Langdon, Microstructure and microtexture in pure copper processed by high-pressure torsion, J. Mater. Sci. 48 (2013) $4563-4572$.

[74] A.P. Zhilyaev, I. Shakhova, A. Belyakov, R. Kaibyshev, T.G. Langdon, Effect of annealing on wear resistance and electroconductivity of copper processed by highpressure torsion, J. Mater. Sci. 49 (2014) 2270-2278.

[75] N. Lugo, N. Llorca, J.M. Cabrera, Z. Horita, Microstructures and mechanical properties of pure copper deformed severely by equal-channel angular pressing and high pressure torsion, Mater. Sci. Eng. A. 477 (2008) 366-371.

[76] A.P. Zhilyaev, I. Shakhova, A. Belyakov, R. Kaibyshev, T.G. Langdon, Wear resistance and electroconductivity in copper processed by severe plastic deformation, 
Wear. 305 (2013) 89-99.

[77] H. Jiang, Y.T. Zhu, D.P. Butt, I. V Alexandrov, T.C. Lowe, Microstructural evolution, microhardness and thermal stability of HPT-processed Cu, Mater. Sci. Eng. A. 290 (2000) 128-138.

[78] X.Z. Liao, Y.H. Zhao, Y.T. Zhu, R.Z. Valiev, D. V. Gunderov, Grain-size effect on the deformation mechanisms of nanostructured copper processed by high-pressure torsion, J. Appl. Phys. 96 (2004) 636-640.

[79] J.T. Wang, Y.K. Zhang, J.F. Chen, J.Y. Zhou, M.Z. Ge, Y.L. Lu, X.L. Li, Effects of laser shock peening on stress corrosion behavior of 7075 aluminum alloy laser welded joints, Mater. Sci. Eng. A. 647 (2015) 7-14.

[80] C. Xu, G. Sheng, H. Wang, Y. Jiao, X. Yuan, Effect of high energy shot peening on the microstructure and mechanical properties of Mg/Ti joints, J. Alloys Compd. 695 (2017) $1383-1391$

[81] A.P. Zhilyaev, S. Swaminathan, A.A. Gimazov, T.R. McNelley, T.G. Langdon, An evaluation of microstructure and microhardness in copper subjected to ultra-high strains, J. Mater. Sci. 43 (2008) 7451-7456.

[82] A.P. Zhilyaev, A.A. Gimazov, E.P. Soshnikova, Á. Révész, T.G. Langdon, Microstructural characteristics of nickel processed to ultrahigh strains by high-pressure torsion, Mater. Sci. Eng. A. 489 (2008) 207-212.

[83] A.H. Chokshi, M.A. Meyers, The prospects for superplasticity at high strain rates: preliminary considerations and an example, Scr. Metall. Mater. 24 (1990) 605-610.

[84] M. Wen, G. Liu, J. Gu, W. Guan, J. Lu, Dislocation evolution in titanium during surface severe plastic deformation, Appl. Surf. Sci. 255 (2009) 6097-6102.

[85] U. Andrade, M.A. Meyers, K.S. Vecchio, A.H. Chokshi, Dynamic recrystallization in high-strain, high-strain-rate plastic deformation of copper. Acta Metall. Mater. 42 
(1994) 3183-3195.

[86] J.A. Hines, K.S. Vecchio, Recrystallization kinetics within adiabatic shear bands, Acta Mater. 45 (1997) 635-649.

[87] L.E. Murr, E. V. Esquivel, Observations of common microstructural issues associated with dynamic deformation phenomena: Twins, microbands, grain size effects, shear bands, and dynamic recrystallization, J. Mater. Sci. 39 (2004) 1153-1168.

[88] M.A. Meyers, U.R. Andrade, A.H. Chokshi, The Effect of Grain Size on the High-Strain, High-Strain-Rate Behavior of Copper, Metall. Mater. Trans. A 26A (1995) 2881-2893.

[89] R.D. Doherty, D.A. Hughes, F.J. Humphreys, J.J. Jonas, D.J. Jensen, M.E. Kassner, W.E. King, T.R. McNelley, H.J. McQueen, A.D. Rollett, Current Issues in Recrystallization: A review, Mater. Sci. Eng. A. 238 (1997) 219-274.

[90] R.D. Doherty, D.A. Hughes, F.J. Humphreys, J.J. Jonas, D.J. Jensen, M.E. Kassner, W.E. King, T.R. McNelley, H.J. McQueen, A.D. Rollett, Current Issues in Recrystallization: A Review, Mater. Today 1 (1998) 14-15.

[91] W.F. Hosford, R.M. Caddell, Metal Forming: Mechanics and Metallurgy, 3rd ed., Cambridge University Press, New York, 2007.

[92] P.H.R. Pereira, Y.C. Wang, Y. Huang, T.G. Langdon, Influence of grain size on the flow properties of an Al-Mg-Sc alloy over seven orders of magnitude of strain rate, Mater Sci. Eng. A 685 (2017) 367-376.

[93] J.Z. Lu, K.Y. Luo, Y.K. Zhang, C.Y. Cui, G.F. Sun, J.Z. Zhou, L. Zhang, J. You, K.M. Chen, J.W. Zhong, Grain refinement of LY2 aluminum alloy induced by ultra-high plastic strain during multiple laser shock processing impacts, Acta Mater. 58 (2010) 3984-3994.

[94] J.Z. Lu, K.Y. Luo, Y.K. Zhang, G.F. Sun, Y.Y. Gu, J.Z. Zhou, X.D. Ren, X.C. Zhang, L.F. Zhang, K.M. Chen, C.Y. Cui, Y.F. Jiang, A.X. Feng, L. Zhang, Grain refinement 
mechanism of multiple laser shock processing impacts on ANSI 304 stainless steel, Acta Mater. 58 (2010) 5354-5362. 


\section{Figures captions:}

Fig. 1 OIM images for oxygen-free copper processed by ECAP for (a) 1, (b) 4 and (c) 8 passes at $298 \mathrm{~K}$.

Fig. 2 Histograms of the misorientation angles of grain boundaries for oxygen-free copper processed by ECAP for (a) 1, (b) 4 and (c) 8 passes at $298 \mathrm{~K}$.

Fig. 3 OIM images for oxygen-free copper processed by ECAP for (a) 1, (b) 4 and (c) 8 passes and further deformed by dynamic testing at a strain rate of $10 \mathrm{~s}^{-1}$ at $298 \mathrm{~K}$.

Fig. 4 Histograms of the misorientation angles of grain boundaries for oxygen-free copper processed by ECAP for (a) 1, (b) 4 and (c) 8 passes and further deformed by dynamic testing at a strain rate of $10 \mathrm{~s}^{-1}$ at $298 \mathrm{~K}$.

Fig. 5 True stress vs true strain for oxygen-free copper processed by ECAP for 1, 4 and 8 passes and further deformed by dynamic testing at a strain rate of $10 \mathrm{~s}^{-1}$ at $298 \mathrm{~K}$. 


\section{Tables captions:}

Table 1 Calculated dislocation density and crystallite size as a function of preliminary number of ECAP passes for oxygen-free copper processed by ECAP and further deformed by dynamic testing using a strain rate of $10 \mathrm{~s}^{-1}$ at $298 \mathrm{~K}$.

Table 2 Dislocation density and grain size for the as-annealed specimen, after processing by ECAP and after ECAP and dynamic testing using a strain rate of $10 \mathrm{~s}^{-1}$ at $298 \mathrm{~K}$ for 1,4 and 8 passes.

Table 3 Comparison between the average grain sizes produced by ECAP followed by dynamic testing with the average grain sizes produced by various SPD techniques in pure copper at room temperature [48, 68-76]. 

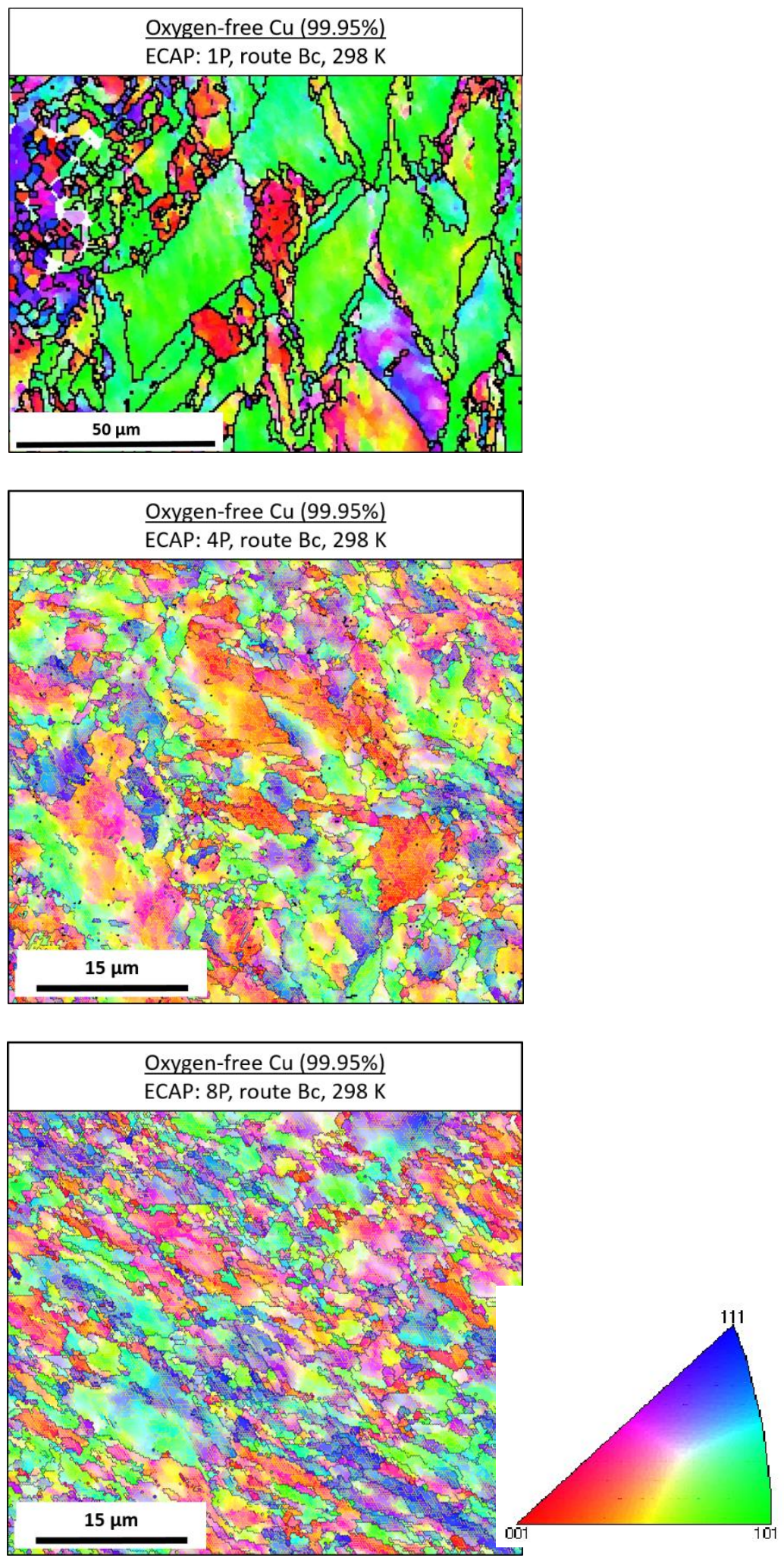

Fig. 1 OIM images for oxygen-free copper processed by ECAP for (a) 1, (b) 4 and (c) 8 passes at $298 \mathrm{~K}$. 

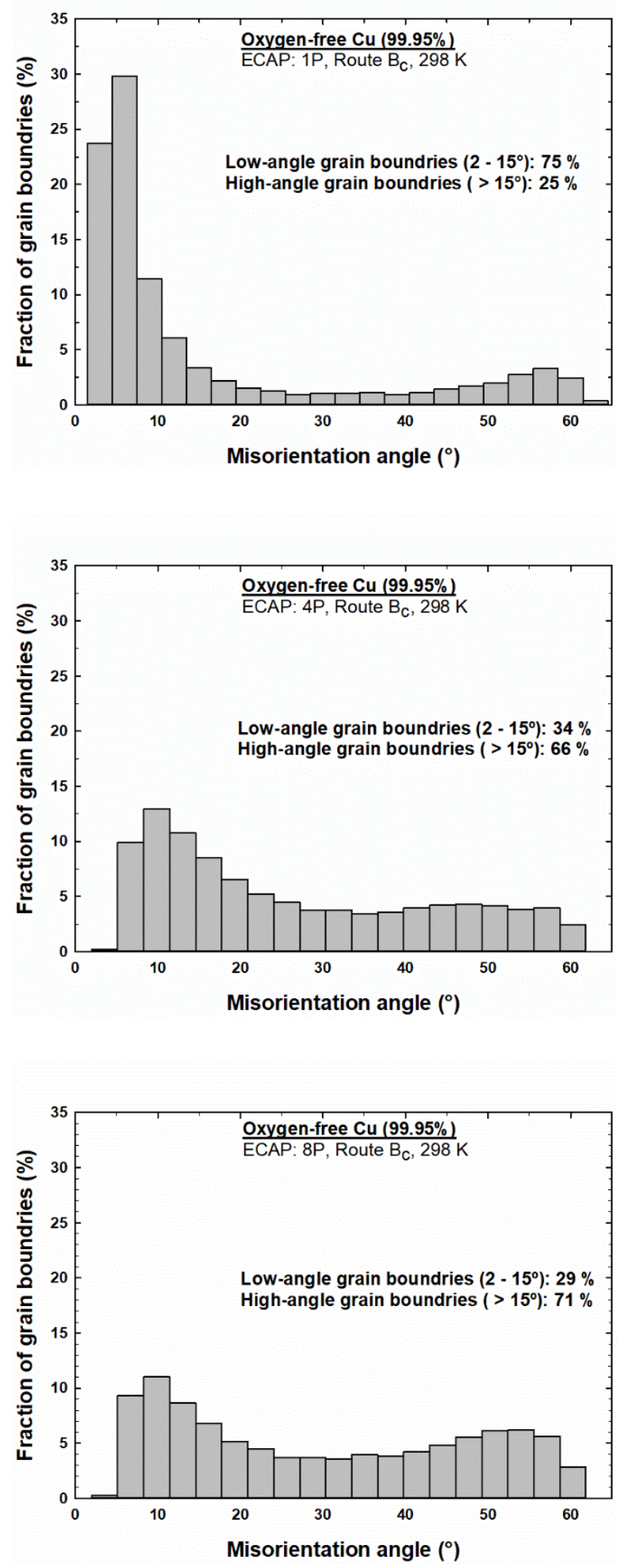

Fig. 2 Histograms of the misorientation angles of grain boundaries for oxygen-free copper processed by ECAP for (a) 1, (b) 4 and (c) 8 passes at $298 \mathrm{~K}$. 

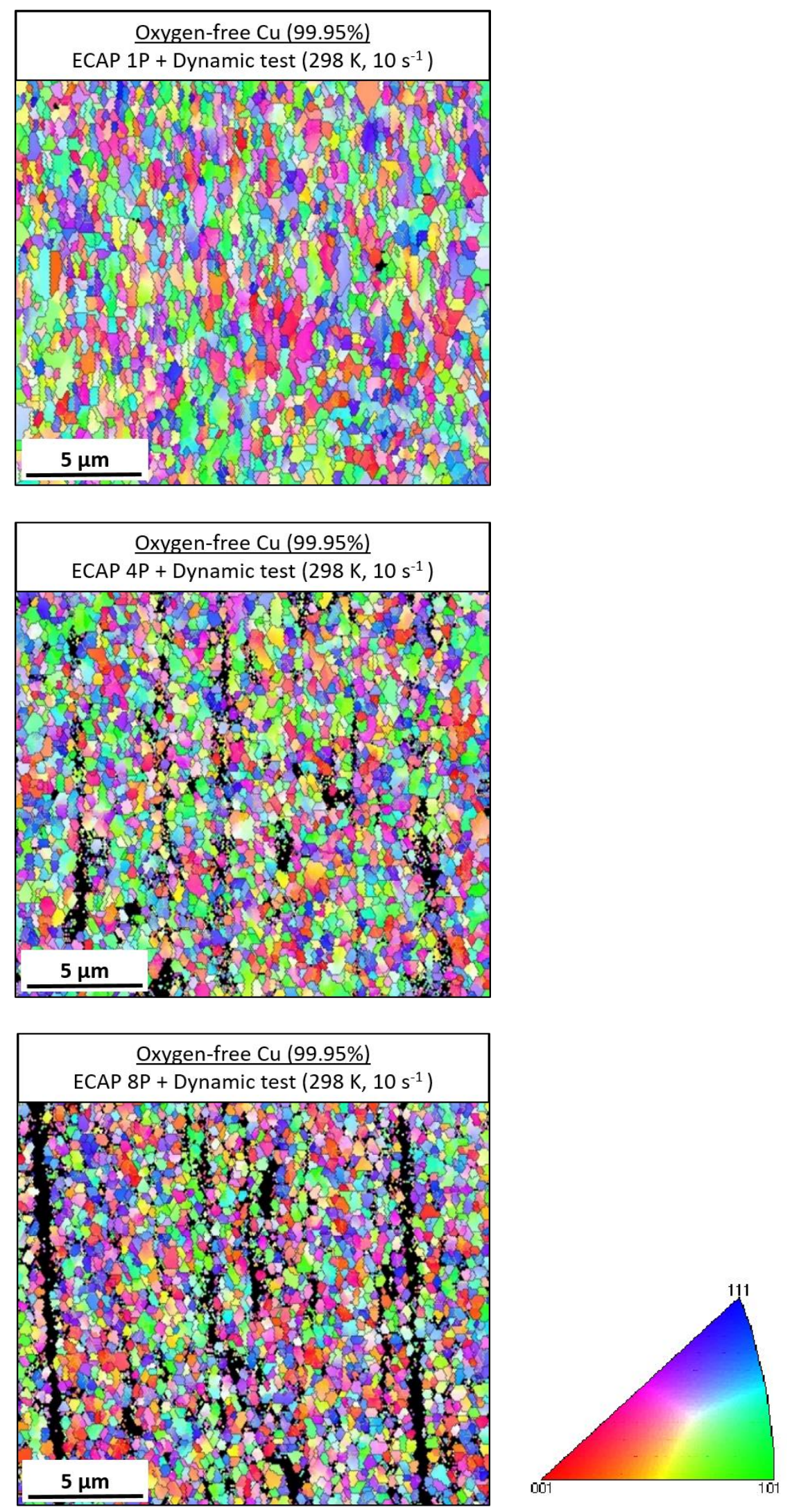

Fig. 3 OIM images for oxygen-free copper processed by ECAP for (a) 1, (b) 4 and (c) 8 passes and further deformed by dynamic testing at a strain rate of $10 \mathrm{~s}^{-1}$ at $298 \mathrm{~K}$. 

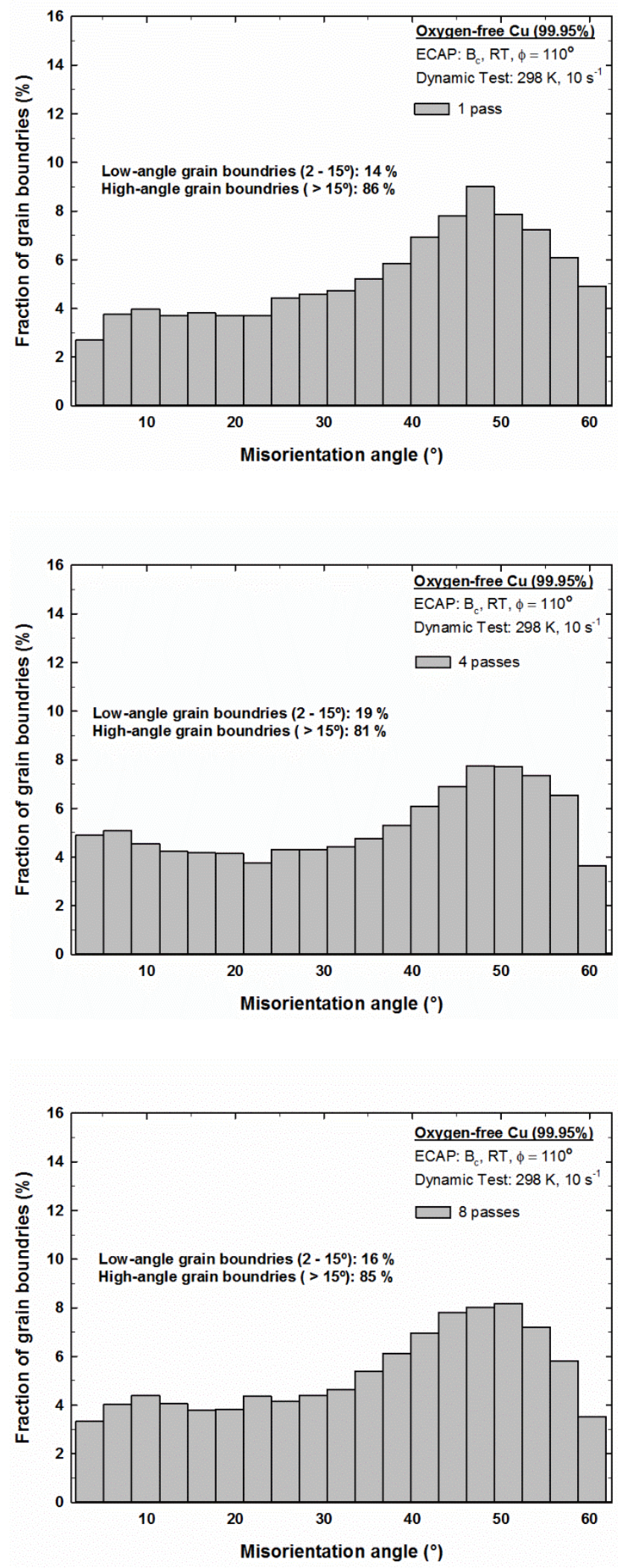

Fig. 4 Histograms of the misorientation angles of grain boundaries for oxygen-free copper processed by ECAP for (a) 1, (b) 4 and (c) 8 passes and further deformed by dynamic testing at $10 \mathrm{~s}^{-1}$ at $298 \mathrm{~K}$. 


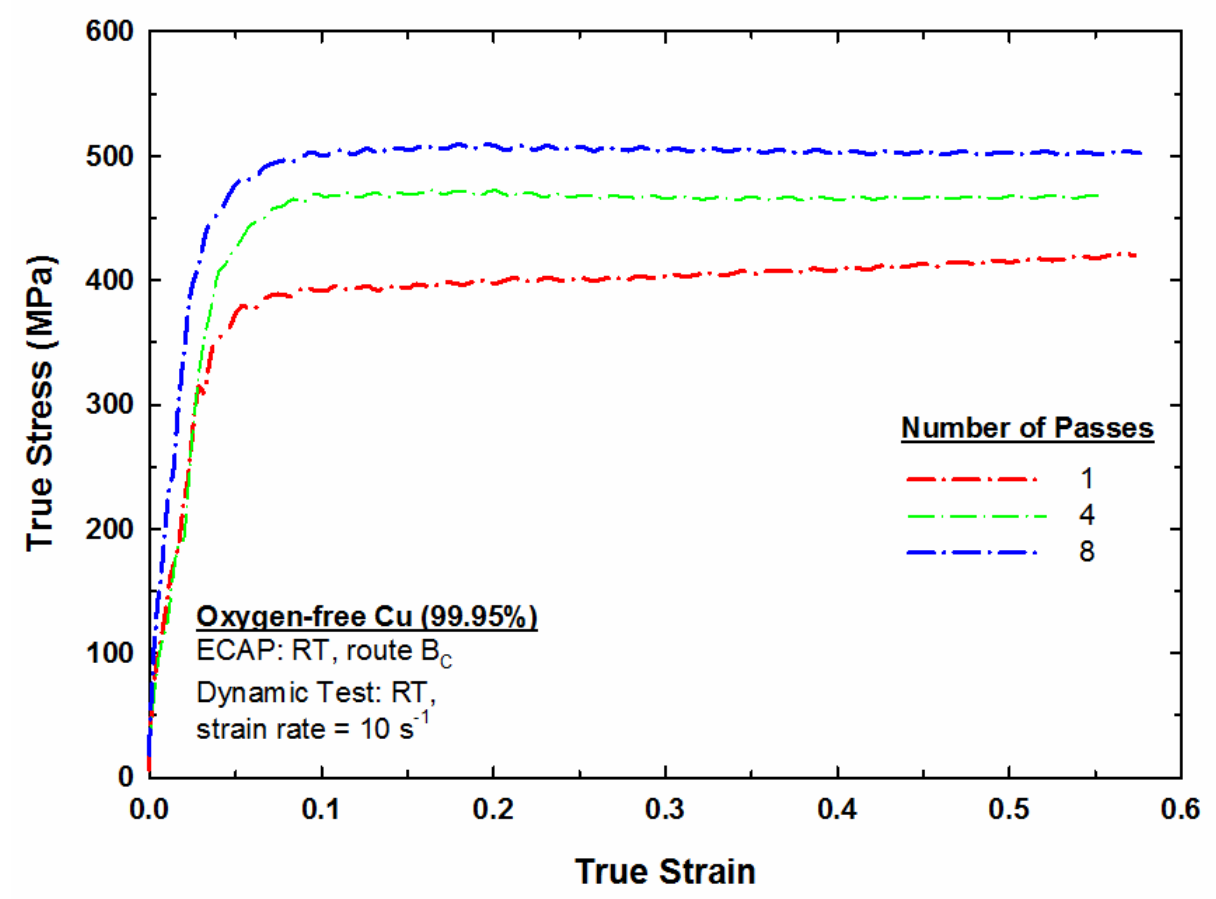

Fig. 5 True stress vs true strain for oxygen-free copper processed by ECAP for 1, 4 and 8 passes and further deformed by dynamic testing at a strain rate of $10 \mathrm{~s}^{-1}$ at $298 \mathrm{~K}$. 
Table 1 Calculated dislocation density and crystallite size as a function of preliminary number of ECAP passes for oxygen-free copper processed by ECAP and further deformed by dynamic testing using a strain rate of $10 \mathrm{~s}^{-1}$ at $298 \mathrm{~K}$.

\begin{tabular}{|c|c|c|}
\hline Number of passes & Crystallite Size (nm) & Dislocation Density $\left.\mathbf{( m}^{-2}\right)$ \\
\hline 1 & 129 & $6.11 \times 10^{13}$ \\
\hline 4 & 81 & $1.12 \times 10^{14}$ \\
\hline 8 & 74 & $1.78 \times 10^{14}$ \\
\hline
\end{tabular}

Table 2 Dislocation density and grain size for the as-annealed specimen, after processing by ECAP and after ECAP and dynamic testing using a strain rate of $10 \mathrm{~s}^{-1}$ at $298 \mathrm{~K}$ for 1,4 and 8 passes.

\begin{tabular}{|c|l|c|c|}
\hline Number of passes & \multicolumn{1}{|c|}{ Condition } & Grain Size $(\mathbf{n m})$ & Dislocation Density $\left.\mathbf{( m}^{-2}\right)$ \\
\hline 0 & As-annealed & 24000 & $3.90 \times 10^{12}$ \\
\hline \multirow{2}{*}{1} & ECAP & 5500 & $3.98 \times 10^{13}$ \\
\cline { 2 - 4 } & ECAP + Dynamic & 400 & $6.11 \times 10^{13}$ \\
\hline \multirow{2}{*}{4} & ECAP & 4400 & $8.20 \times 10^{13}$ \\
\cline { 2 - 4 } & ECAP + Dynamic & 330 & $1.12 \times 10^{14}$ \\
\hline \multirow{2}{*}{8} & ECAP & 2900 & $3.60 \times 10^{14}$ \\
\cline { 2 - 4 } & ECAP + Dynamic & 300 & $1.78 \times 10^{14}$ \\
\hline
\end{tabular}


Table 3 Comparison between the average grain sizes produced by ECAP ( $\mathrm{P}=$ passes $)$ followed by dynamic testing with the average grain sizes produced by various SPD techniques in pure copper at room temperature [48, 68-76]. For HPT processing, $\mathrm{T}=$ turns.

\begin{tabular}{|c|c|c|c|}
\hline Material & Reference & Grain size $(\mathbf{n m})$ & Technique \\
\hline Oxygen-free $\mathrm{Cu}(99.95)$ & Present study & 400 & ECAP $(1 \mathrm{P})+$ dynamic test (compressive strain $\varepsilon=0.68)$ \\
\hline Oxygen-free $\mathrm{Cu}(99.95)$ & Present study & 330 & ECAP $(4 \mathrm{P})+$ dynamic test (compressive strain $\varepsilon=0.68)$ \\
\hline Oxygen-free $\mathrm{Cu}(99.95)$ & Present study & 300 & ECAP $(8 \mathrm{P})+$ dynamic test (compressive strain $\varepsilon=0.68$ ) \\
\hline Pure $\mathrm{Cu}(99.96 \%)$ & \begin{tabular}{|l} 
Horita and Langdon (2005) \\
[68]
\end{tabular} & 140 & HPT (5T) \\
\hline Pure $\mathrm{Cu}(99.98 \%)$ & Lugo et al. (2010) [69] & 500 & ECAP (8P) \\
\hline Pure Cu (99.995\%) & Wang et al. (2006) [70] & 100 & $\begin{array}{l}\text { SMAT (surface mechanical attrition treatment for } 30 \\
\text { min) }\end{array}$ \\
\hline Pure $\mathrm{Cu}(99.9 \%)$ & Zhilyaev et al. (2008) [71] & 320 & $\mathrm{HPT}(5 \mathrm{~T})$ \\
\hline Pure $\mathrm{Cu}(99.9 \%)$ & Zhilyaev et al. (2008) [71] & 500 & ECAP (4P) \\
\hline Pure $\mathrm{Cu}(99.9 \%)$ & Zhilyaev et al. (2008) [71] & 310 & $\operatorname{ECAP~(4P)~+~HPT~(5T)~}$ \\
\hline $\begin{array}{l}\text { Oxygen-free } \mathrm{Cu} \\
(99.98 \%)\end{array}$ & Dobatkin et al. (2007) [72] & 230 & ECAP $(25 \mathrm{P})$ \\
\hline OFHC Cu $(99.99+\%)$ & Al-Fadhalah et al. (2013) [73] & 450 & HPT (5T) \\
\hline Pure $\mathrm{Cu}$ & Zhilyaev et al. (2014) [74] & 370 & HPT (5T) \\
\hline Pure $\mathrm{Cu}(99.96 \%)$ & Komura et al. (1999) [20] & 270 & ECAP (10P) \\
\hline Pure $\mathrm{Cu}(99.98 \%)$ & Lugo et al. (2008) [75] & $150-300$ & ECAP (8P) \\
\hline Pure $\mathrm{Cu}(99.98 \%)$ & Lugo et al. (2008) [75] & $100-300$ & HPT (5T) \\
\hline Pure $\mathrm{Cu}(99.98 \%)$ & Lugo et al. (2008) [75] & $400-700$ & ECAP (8P) + HPT (5T) \\
\hline Pure $\mathrm{Cu}(99.99 \%)$ & Zhilyaev et al. (2013) [76] & 210 & ECAP (4P) + HPT (5T) \\
\hline Pure $\mathrm{Cu}(99.995 \%)$ & Li et al. (2008) [48] & $\begin{array}{l}49 \mathrm{~nm} \text { in transverse } \\
\text { direction (grain size aspect } \\
\text { ratio } 2: 1 \text { ) }\end{array}$ & DPD (dynamic plastic deformation, strain $\varepsilon=2.1$ ) \\
\hline
\end{tabular}

